\title{
Influence of Guangxi LUCC Process on Farmland Potential Productivity in Recent 20 Years
}

\author{
Xu Jinyong, Zhang Zengxiang, Zhao Xiaoli, Wang Xiao, Yi Ling, Liu Bin \\ Institute of Remote Sensing and Digital Earth \\ Chinese Academy of Sciences \\ Beijing, China \\ xu_jy@irsa.ac.cn
}

\begin{abstract}
The changing process of Guangxi farmland resource in recent 20 years was analyzed via 5 periods of land use data abstracted by remote sensing technique in this paper; farmland potential productivity was estimated and influence of LUCC process on farmland potential productivity was analyzed by combining with daily meteorological data from 1990 to 2010 and adopting environmental factor successive correction model. According to the remote sensing monitoring result, Guangxi farmland area was decreased by $20,843.81 \mathrm{hm}^{2}$ in recent 20 years. Under average climate conditions from 1990 to 2010, farmland change has made the mean value of farmland potential productivity in Guangxi an accelerated decline trend. The mean value of farmland potential productivity for reclaimed farmland was $6,013.44 \mathrm{Kg} / \mathrm{hm}^{2}$, and that for lost farmland was $11,408.11 \mathrm{Kg} / \mathrm{hm}^{2}$, so the quality of reclaimed farmland cannot catch up with that of lost farmland. In all farmland changes, the dynamic type of turning forest into farmland contributes the most to the increase of gross farmland potential productivity, occupying $80.73 \%$ of total value for reclaimed farmland; the dynamic type of turning farmland into construction land decreased gross farmland potential productivity by the most, occupying $\mathbf{7 4 . 3 9 \%}$ of total value for lost farmland.
\end{abstract}

Index Terms-Farmland, potential productivity, Guangxi.

\section{INTRODUCTION}

Farmland and agricultural climate resource are two basic conditions which deciding the development of regional agriculture. Climatic variation affects productivity by controlling optothermal and moisture conditions in the growth process of crops; while land use / land cover change (LUCC) will influence farmland productivity by directly changing the quantity and quality of agricultural land resource as well as agricultural land use structure[1]. Scientific comprehension about temporal-spatial trends of farmland area and farmland capacity has practical significance for farmland protection, food safety, and reasonable planning of agricultural production.

Farmland potential productivity refers to the potential ability of farmland to produce biological products required by human continuously under a certain condition, and it is the important basis for studying farmland capacity. Domestic and overseas scholars have used different models to study potential productivity, but research on the influence of farmland change is still at the initial stage. Besides, the adopted farmland spatial distribution data are aimed at an early stage and there are few studies directed at recent years[2]. Moreover, time series of the adopted farmland spatial distribution data is short and it cannot reflect the influencing process of farmland change on farmland potential productivity. There is still no study about influence of recent farmland change on farmland potential productivity in Guangxi at present. In this paper, farmland spatial distribution data with long time series were overlaid by spatial distribution data of climatic potential productivity to analyze the changing process of Guangxi farmland potential productivity, thus study the influence of land use change on farmland potential productivity, and provide scientific foundation for relevant decisions.

\section{RESEARCH METHOD}

\section{A. General situation of research area}

Guangxi is located along the coast in the south of China, between $104^{\circ} 26^{\prime} \sim 112^{\circ} 4^{\prime} \mathrm{E}$ and $20^{\circ} 54^{\prime} \sim 26^{\circ} 24^{\prime} \mathrm{N}$, with the tropic cancer traversing the center of the whole region, and it has subtropical humid monsoon climate. Guangxi is adjacent to Nanling Mountains in the north, has Yunnan-Guizhou Plateau in the west, and faces the tropical ocean in the south. It is the transitional zone from Yunnan-Guizhou Plateau to coastal hills; it is low in the middle, similar to a basin, with the geological features of multiple mountainous regions and few plains.

\section{B. Data basis}

Vector land use data of Guangxi come from the land use database of Institute of Remote Sensing and Digital Earth, Chinese Academy of Sciences, including 5 periods: the end of the 1980s, 2000, 2005, 2008 and 2010. The land use data was abstracted by eye interpretation method based on satellite images like Landsat TM, CBERS CCD and HJ-1 CCD, and with a proportional scale of 1:100,000. Farmland information was abstracted from land use data under GIS environment and it was then converted into $100 \mathrm{~m} \times 100 \mathrm{~m}$ raster data. 
Meteorological data include daily temperature, precipitation, relative humidity, wind speed, sunshine duration, etc. of 23 meteorological sites with continuous observation data from 1990 to 2010 in Guangxi, and they were reorganized by Data Center of China Meteorological Administration. Firstly, all meteorological data were analyzed and organized via computer program, including disposal like correlation analysis, elimination of bad data, replacement of missing value, and analysis of variation trend; then statistic was made for daily meteorological data of these 23 meteorological sites from 1990 to 2010 by ten days, and ten-day meteorological data like total precipitation, average temperature, average relative humidity, average wind speed and average sunshine duration in each ten days of the month were calculated.

\section{Calculation of farmland potential productivity}

This paper adopted the environmental factor successive correction model to calculate farmland potential productivity. The model conducts the calculation by steps: photosynthetic potential productivity $\rightarrow$ light and temperature potential productivity $\rightarrow$ climatic potential productivity $\rightarrow$ farmland potential productivity. For easy of use, the environmental factor successive correction model was widely adopted in China[1,3].

The climatic potential productivity was calculated by considering the attenuation influences of temperature, precipitation variations, as well as the crop harvest index on photosynthetic potential productivity (Eq. 1).

$$
Y_{C}=C_{H} \sum_{i=1}^{n} Y_{P i} \times f\left(T_{i}\right) \times f\left(W_{i}\right)
$$

In Eq. 1, where $i=1,2, \ldots, n$, means the sequence number of every ten days within the crop growing season; $Y_{P i}$ is the photosynthetic potential productivity of each ten days $(\mathrm{Kg} / \mathrm{hm} 2)$; $f\left(T_{i}\right)$ is the temperature correction coefficient; $f\left(W_{i}\right)$ is the moisture correction coefficient; $C_{H}$ is crop harvest index. The constant value of $C_{H}$ and solar radiation parameters for calculating the photosynthetic potential productivity refers to paper[4-7]. For $f\left(T_{i}\right)$, the temperature influence formula of LI Kehuang was adopted for chimonophilous crops (like wheat), and that of HOU Guangliang was adopted for thermophilic crops (like rice and corn) were adopted[8-9]. The possible evapotranspiration amount was calculated according to Modified Penman Formula recommended and modified by FAO56 in 1998 for determine the value of $f\left(T_{i}\right)$.

Firstly, this paper caculated the climatic potential productivity of main food crops in 23 meteorological sites of Guangxi, in which paddy field crops include early rice, late rice and middleseason rice, and dry crops cover winter wheat, spring corn and summer corn. Climatic potential productivity of various food crops was calculated according to the single season, and the growing seasons of various food crops were determined according to The Agriculture Phenology Atlas of China[10]. Then, the spatial distribution of climatic potential productivity of main food crops were obtained by adopting the spline interpolation method for the 23 meteorological sites, and the output raster resolution was $100 \mathrm{~m} \times 100 \mathrm{~m}[11]$, and double standard parallels Area Conic projection (Albers) which has the same projection basis with land use data was adopted. Farmland potential productivity was obtained by further considering the influence of land use on climatic potential productivity. Finally, because the crop specie of different farmland patches was unknown, the average climatic potential productivity of paddy field crops and dry crops was calculated to represents the farmland potential productivity for paddy field and dry land respectively.

\section{RESULT AND ANALYSIS}

\section{A. Farmland changes in Guangxi}

The reclaimed farmland area from the end of the 1980s to 2010 in Guangxi was 44,685.13 $\mathrm{hm}^{2}$ in total, transferring from farmland to other land use types has decreased the farmland area by $65,528.95 \mathrm{hm}^{2}$, and the net decrease of farmland area was 20,843.81 $\mathrm{hm}^{2}$ (Fig. 1). Occupation and supplementation of Guangxi farmland amount from the end of the 1980s to 2010 was out of balance, with lost farmland area greater than that of reclaimed.

Increase of Guangxi farmland mainly happened from the end of the 1980 s to 2000 , the increased area was $42,094.35 \mathrm{hm}^{2}$; increase of farmland area was smaller during the periods from 2000 to 2010 , which was $2,590.79 \mathrm{hm}^{2}$. Forest supplied most land for farmland reclamation, with an area of $37,266.33 \mathrm{hm}^{2}$, occupying $83.40 \%$ of increased farmland area; grassland that has been turned into farmland took the second place, with an area of $5,423.23 \mathrm{hm}^{2}$, occupying $12.14 \%$ of increased farmland area; water that has been turned into farmland took the third place, with an area of $1,866.59 \mathrm{hm}^{2}$, occupying $4.18 \%$ of increased farmland area; construction land that has been turned into farmland was the smallest, with an area of $128.99 \mathrm{hm}^{2}$, occupying $0.29 \%$ of increased farmland area.

Guangxi farmland area has been transformed out by $33,921.39 \mathrm{hm}^{2}$ from 2000 to 2010 , which was $31,607.56 \mathrm{hm}^{2}$ from the end of the 1980s to 2000, so the rate of farmland loss has been accelerated. During the 20 years, farmland that has been turned into construction land most, with an area of $46,654.50 \mathrm{hm}^{2}$, occupying $71.20 \%$ of lost farmland area; farmland that has been turned into forest took the second place, with an area of 9,365.87 $\mathrm{hm}^{2}$, occupying $14.29 \%$ of lost farmland area; farmland that has been turned into water area took the third place, with an area of $9,207.95 \mathrm{hm}^{2}$, occupying $14.05 \%$ of lost farmland area; farmland that has been turned into grassland was the smallest, with an area of $300.62 \mathrm{hm}^{2}$, occupying $0.46 \%$ of lost farmland area. 


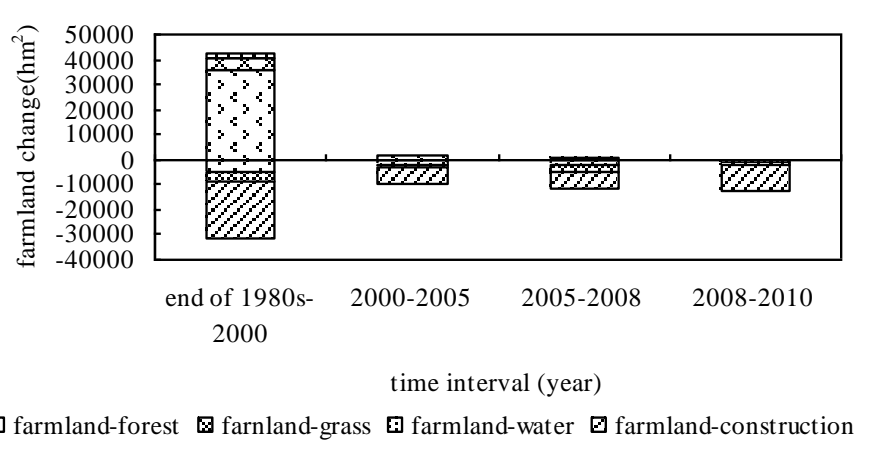

Fig. 1. Farmland area Changes of Guangxi from the late 1980s to 2010

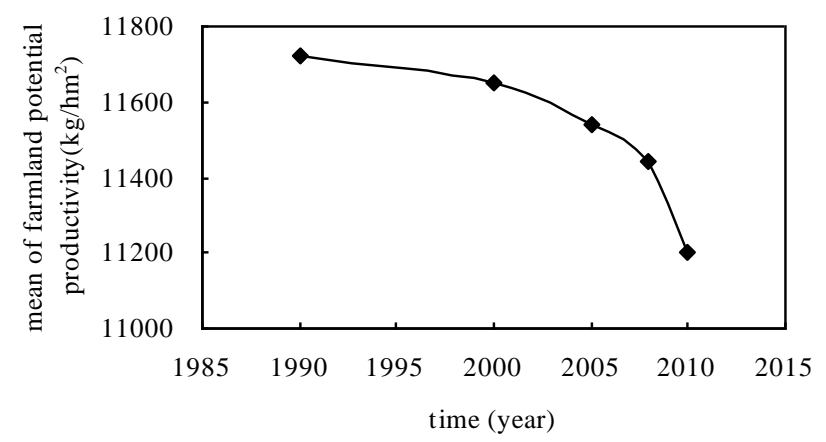

Fig. 2. The changes of mean potential productivity for farmland of Guangxi from 1990 to 2010 under the multi-year average climatic conditions

\section{$B$. Influence of farmland change on farmland potential productivity}

Raster data of average climatic potential productivity from 1990 to 2010 in Guangxi were overlaid by spatial distribution raster data of farmland during different periods to analyze the mean value change of farmland potential productivity during different periods. Under average climate conditions from 1990 to 2010, land use change from 1990 to 2010 has made the mean value of farmland productivity in Guangxi present the decline trend (Fig. 2).

Under average climate conditions from 1990 to 2010, the mean value of farmland potential productivity changes gently from 1990 to 2010, with an annual decline of about $7.05 \mathrm{Kg} / \mathrm{hm}^{2}$; the decline rate from 2000 to 2008 was increased obviously, with an annual decline of $26.05 \mathrm{Kg} / \mathrm{hm}^{2}$; the decline rate was the highest during the period from 2008 to 2010 , with an annual decline of $118.22 \mathrm{Kg} / \mathrm{hm}^{2}$.

Raster data of land use change from the end of the 1980s to 2010 were overlaid by raster data of average climatic potential productivity from 1990 to 2010 in Guangxi, to analyze the corresponding mean value of farmland potential productivity for various farmland dynamic types. The influence of land use change on farmland potential productivity was different from 1990 to 2010; the corresponding mean value of farmland productivity for the loss farmland was always greater than that of reclaimed farmland.
In terms of the land use change type referred to farmland loss, the corresponding mean value of farmland potential productivity for the dynamics that farmland transformed into water area was the greatest, which was $13,195.92 \mathrm{Kg} / \mathrm{hm}^{2}$; the dynamics of turning farmland into construction land took the second place, with the corresponding farmland potential productivity mean value of $11,869.49 \mathrm{Kg} / \mathrm{hm}^{2}$; the dynamics of turning farmland into forest took the third place, with the corresponding farmland potential productivity mean value of $7,168.02 \mathrm{Kg} / \mathrm{hm}^{2}$; the corresponding farmland potential productivity mean value for the dynamics of turning farmland into grassland was the smallest, which was $6,591.70 \mathrm{Kg} / \mathrm{hm}^{2}$. In terms of the land use change type referred to farmland reclamation, the corresponding farmland potential productivity mean value for the dynamics of turning water area into farmland was the greatest, which was $9,030.25 \mathrm{Kg} / \mathrm{hm}^{2}$; the dynamics of turning grassland into farmland took the second place, with the corresponding farmland potential productivity mean value of $6,440.05 \mathrm{Kg} / \mathrm{hm}^{2}$; the corresponding farmland potential productivity mean values for the dynamics of turning forest and construction land into farmland were relatively small, which were $5,908.23 \mathrm{Kg} / \mathrm{hm}^{2}$ and $5,977.85 \mathrm{Kg} / \mathrm{hm}^{2}$ respectively (Fig. 3). Generally speaking, the potential productivity mean value of reclaimed farmland in Guangxi from 1990 to 2010 was $6,013.44 \mathrm{Kg} / \mathrm{hm}^{2}$, and the potential productivity mean value of lost farmland was $11408.11 \mathrm{Kg} / \mathrm{hm}^{2}$, so quality of reclaimed farmland cannot catch up with that of lost farmland.

Product of the corresponding farmland potential productivity mean value for farmland change type and its area was calculated to analyze the influence of land use change on the gross farmland potential productivity (Fig. 4). Reclaimed farmland has increased gross farmland potential productivity by $272,700 t$ from 1990 to 2010, transformation of farmland into other land use types has decreased gross farmland potential productivity by $744,400 t$, and the difference value between these two was 471,700t. Forest land was the main source for farmland area increase from the end of the 1980s to 2010, but meanwhile, expansion of construction land occupies many farmland areas. Combined with analysis of the impact of various farmland dynamic on farmland potential productivity, it was obtained that the land use change type of turning forest land into farmland contributes the most to increase of gross farmland potential productivity in Guangxi, with an increase of $220,200 t$, occupying $80.73 \%$ of total value of reclaimed gross farmland potential productivity; the land use change type of turning farmland into construction land decreased gross farmland potential productivity in Guangxi by the most, with a decrease of 553,800 t, occupying $74.39 \%$ of total value of lost gross farmland potential productivity.

\section{Suggestion for farmland protection in Guangxi}

Farmland is the foundation resource for human survival and development. Along with economy developing, farmland resource should be protected; stability of farmland amount should 
be guaranteed and loss of high-quality farmland should be decreased. Abundant of mountainous, hills and tablelands, lack of flats and waters are main features for Guangxi topography, so there is lack of reserve resources for farmland; besides, the reserved resources are scattered in space, traffic and water conditions are poor, so the cost for farmland reclamation is high[12]. However, Guangxi is an important province of western development in China, its economy developed rapidly in recent years, and more and more farmland resources have been occupied and transformed into construction land, so protection of its farmland resources faced with a severe challenge. Therefore, farmland protection measures should be strengthened, such as works on reclamation and consolidation of new farmland, fully exploit the existing stock of construction land potential, underutilized idle land, thereby reducing the occupation of cultivated land resources for construction land. When stressing on the balance between occupation and reclamation of farmland, should pay attention to the quality balance of farmland. On the one hand, to prevent the reduction of the high quality farmland, on the other hand,

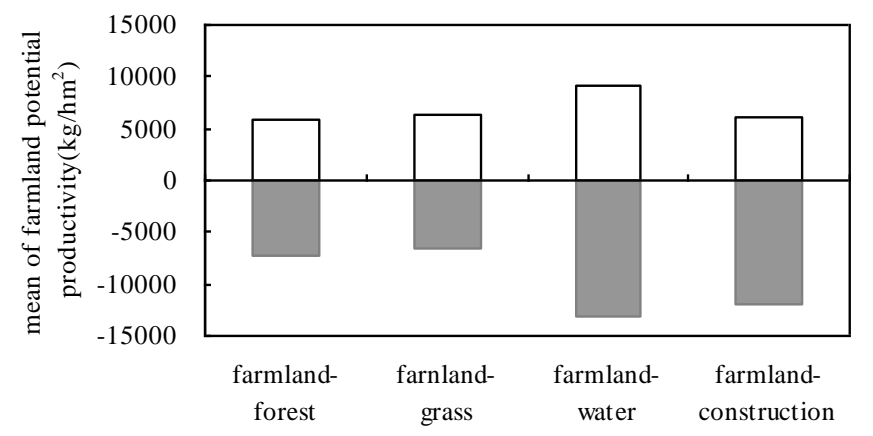

The value is greater than 0 indicates that a variety of other land use types converted to farmland; conversely, arable land into a variety of other land use types.

Fig. 3. The impact of landuse on potential productivity of farmland in recent 20 years

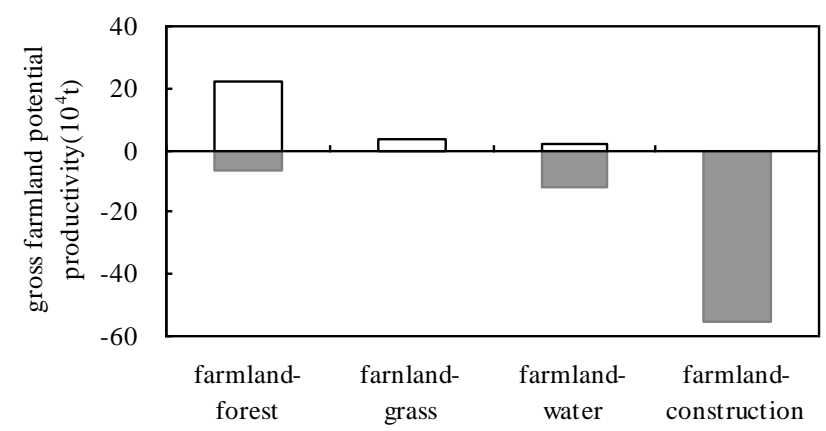

The value is greater than 0 indicates that a variety of other land use types converted to farmland; conversely, arable land into a variety of other land use types.

Fig. 4. The impact of landuse change on gross potential productivity of farmland in recent 20 years by taking land reform and water-saving irrigation measures to improve the water and fertilizer conditions of low-yielding fields, so as to build high and stable yield efficient basic farmland and improve the overall grain production capacity, therefore, make up for the loss of food production caused by reduction of high quality farmland.

\section{CONCLUSION}

In this paper, the temporal-spatial process of Guangxi farmland resources from the end of the 1980s to 2010 was analyzed; environmental factor successive correction model was adopted to estimate the influence of land use change on farmland potential productivity in Guangxi. The main conclusions were as follows:

The LUCC process in Guangxi from the end of the 1980s to 2010 decreases the farmland area by $20,843.81 \mathrm{hm}^{2}$. Farmland reclamation was dominated by turning forest land into farmland, occupying $83.40 \%$ of reclaimed area; farmland loss was dominated by turning farmland into construction land, occupying $71.20 \%$ of lost area.

Under average climate conditions in recent 20 years, farmland change has made the mean value of farmland potential productivity in Guangxi an accelerated decline trend. The mean value of farmland potential productivity for reclaimed farmland from 1990 to 2010 was $6,013.44 \mathrm{Kg} / \mathrm{hm}^{2}$, and the potential productivity mean value of lost farmland was $11,408.11 \mathrm{Kg} / \mathrm{hm}^{2}$, as a result the quality of reclaimed farmland cannot catch up with that of lost farmland.

In all farmland changes, the dynamic type of turning forest into farmland contributes the most to the increase of gross farmland potential productivity, occupying $80.73 \%$ of total value for reclaimed farmland; the dynamic type of turning farmland into construction land decreased gross farmland potential productivity by the most, occupying $74.39 \%$ of total value for lost farmland.

\section{ACKNOWLEDGMENT}

The study was sponsored by National 908 Project(No. 2010CB95090102).

\section{REFERENCES}

[1] Liu J Y, Xu X L, Zhuang D F, Gao Z Q, "The impacts of LUCC process to light and temperature potential productivity of Chinese cultivated land-based on climatic detection data and remote sensing dynamic land use data," Science in China Series D: Earth Sciences, vol.35, pp. 483-492, August 2005.

[2] Chen C Z, Yang X H, Li Y J, Ji Y X, "The effects of cultivated land change on regional potential productivity in China from 2005 to 2008," JOURNAL OF GEO-INFORMATION SCIENCE, vol.12, pp. 620-627, May 2010.

[3] Gu D Y, Liu J G, Yang Z Q, Yin J, "Reviews on crop productivity potential researches," Agricultural Research in the Arid Areas, vol.25, pp. 89-94, September, 2007. 
[4] Guo J P, Gao S H, Pan Y R, "Agroclimatic potentially development application and countermeasures in Northeast China," Meteorological Monthly, vol.21, pp. 3-9, 1995.

[5] Wang S Y, Huo Z G, Li S K, Xue C Y, Mao F, "Water deficiency and climatic productive potentialities of winter wheat in north of China: study on its dynamic change in recent 40 years," JOURNAL OF NATURAL DISASTERS, vol.11, pp. 121-130, February 2003.

[6] Xiao H J, Jiang T M, Xia J H, Deng Y, “Analysis and calculation of main crop potential productivity in Guizhou," Southwest China Journal of Agricultural Sciences, vol.17, pp. 580-583, March 2004.

[7] Liu B, Yang X G, Wang S G, "Calculation and analysis of climate productive potential of major grain crops in Northeast China," Journal of Jilin Agricultural Sciences, vol.37, pp. 57-60, 2012.
[8] Li K H, "Estimation and analysis of crop potential productivity in Henan," Chinese Journal of Agrometeorology, vol.3, pp. 6-11, 1981.

[9] Hou G L, Liu Y F, "The climate productivity and its regionalization in China," Natural Resources, vol.19, pp. 52-59, 1985.

[10] Zhang F C, Wang D H, Qiu B J, “The agriculture phenology atlas of China," Science Press, Beijing, pp. 1-60, 1987.

[11] Wang L C, Wang G Q, Yang J B, Yang J F, Tian Y, "Spatial interpolation method of crop productive potentiality for the classification of agricultural land," Transactions of the CSAE, 2006, vol.22, pp. 89-93, February 2006.

[12] Lu S N. "Cultivated land changes and its reasons in Guangxi," Agricultural research and application, vol.136, pp. 54-57, September, 2011. 